+1158 SIMULTANEOUS ADMINISTRATION OF TWO LIVE INFLUENZA VACCINES. P.F. Wright, M. Bhargava, J. Thompson, D.T. Karzon. Vanderbilt University, Nashville.

Live, attenuated, intranasally administered influenza A vaccines are being actively evaluated for influenza protection in children. For practical and theoretical reasons, it is important to know if two influenza vaccine strains can be administered simultaneously. Towards this end, cold-adapted $\mathrm{H} 1 \mathrm{~N} 1$ and $\mathrm{H} 3 \mathrm{~N} 2$ vaccines at an equivalent dose $\left(10^{6.5} \mathrm{TCID}_{50}\right)$ were mixed and administered intranasally to 18 doubly seronegative children. Nasal washes were collected daily for 10 days to document virus shedding. Virus was grown in the presence of type specific antisera to determine strains being shed. Plaques were picked at a terminal dilution and hemagglutinins and neuraminidases were characterized to detect reassortant $(\mathrm{H} 3 \mathrm{~N} 1$ or H1N2) virus. Clinically the simultaneous administration of vaccine was well tolerated with no increase in respiratory symptoms when compared to 4 placebo controls in the trial or to previous studies in which each vaccine strain was given independently. H1N1 virus shedding predominated particularly between days $6-10$ when there were 44 instances of H1N1 virus recovery vs 19 instances of $\mathrm{H} 3 \mathrm{~N} 2$. Reassortant plaques were recovered with $3 \mathrm{H} 3 \mathrm{~N} 1$ and $21 \mathrm{H} 1 \mathrm{~N} 2$ plaques among 97 analyzed indicating the potential for influenzal reassortment (a mechanism for emergence of new strains) in the human host. An HAI serologic response was shown to H1N1 in $13(72 \%)$ and to H3N2 in $12(67 \%)$ by 6 weeks after vaccination. This compares to $57 \%(50 / 87)$ seroconversion with the H1N1 vaccine and $85 \%(40 / 47)$ with the $\mathrm{H} 3 \mathrm{~N} 2$ vaccine when each was given alone. Two influenza strains of similar attenuation (each contain identical cold-adapted A/Ann Arbor $/ 6 / 60$ internal genes) may be given simultaneously with only minimal interference with $\mathrm{H} 3 \mathrm{~N} 2$ virus shedding and serologic response. This observation greatly increases the potential utility of these vaccines.

\section{A PROSPECTIVE SEROEPIDEMIOLOGICAL SURVEY OF HERPES
+1150 SIMPLEX (HSV) INFECTIONS IN A COLLEGE POPULATTON} 11159 E. Wu*, J.Sayxe, E.Wiesmeier, D.Bernstein, B.Visscher, Y. Bryson; UCIA Sch. Med., Ios Angeles, Ca.

The true incidence of HSV2 infections in a young, sexually acThe true incidence of HSV2 infections in a young, sexually ac
tive population and its relationship to prior HSV AB status is tive population and its relationship to prior HSV AB status is
unknown. Acquisition of HSVI AB increases with age, inversely correlates with socioecononic status, and modifies HSV2 infections. A prospective seroepidemiologic survey of HSV infections in a predominantly upper and middle class college population(658 enrolled mean age 20.2 yrs, 768 sexually active) without a history of genital HSV infection was initiated. Students were followed by active clinical surveillance and by 6 mos serology. After screening for HSV $A B$ by immunofluorescence (IFA), type specific $A B$ responses were studied by western blot analysis (WBA). To date $36.6 \%$ of 562 stur dents had previous HAV AB by IFA. Seventy-six 8 (237/371) of those <age 21 were seronegative. No significant differences of gender, ethnicity, geography, income, type of or frequency of sexual activity between seropositive and seronegative groups were found. of 226 serological fups at 12 mos ( 125 initially seronegative), 2 (1.5\%) seroconverted asymptomatically by IFA with HSV type I AB by WBA. Over 12 mos FU (562 students), 4 confirmed first episode symptomatic genital HSV outbreaks occurred $(0.78)$. Two had primary genital HSV (1. HSV1, 1 HSV2); 2 had first episode nonprimary (prior HSVl AB) genital outbreaks; 1 had HSVl virus isolated. In (prior HSVl AB) genital outbreaks; 1 had HSVl virus isolated. In
29 FU sera (2 with prior HSV2, 27 with prior HSV1 AB), none have seroconverted to the respective HSV type asymptomatically by WBA. In a susceptible, sexually active population in 12 mos FU, the incidence of symptomatic, genital HSV disease, particularly HSV2 disease, appears to be lowl.

LOW DOSE ENDOTOXIN (EN) AND FIBRONECTIN (FN)

1160 DEPLETION IN RATS: A MODEL OF REYE'S SYNDROME. 1100 M. Hummeler, $\frac{\text { M.C. Yoder, M. Yudkoff, J. Chatten, C. Stanley, }}{\text { S.Douglas, R.A. Polin. Dept. of Peds., Univ. of Pa. Sch. }}$ Med., Philadelphia, PA.

Plasma FN concentrations are decreased in Reye's Syndrome. FN depletion in experimental animals potentiates the systemic effects of EN. The purpose of this study was to determine the effect of FN depletion on the response to endotoxin. Sprague-Dawley male rats $(n=30)$ were entered into 4 groups: (C) Control (D 5W IV), (F) FN depletion ( $1 \%$ gelatin 15 $\mathrm{mg} / \mathrm{kg} \mathrm{IV})$, (E) E. coli EN $(0.2 \mathrm{mg} / \mathrm{kg} \mathrm{IP})$, and (FE) $1 \%$ gelatin $(15 \mathrm{mg} / \mathrm{kg} \mathrm{IV})$ followed in one hour with $\mathrm{EN}\left(0.2 \mathrm{mg} / \mathrm{kg}\right.$ IP). Serum ammonia $\left(\mathrm{NH}_{3}\right)$, free fatty acids (FFA), lactate, glucose, SGOT and SGPT were obtained prior to fasting (baseline), 12 hours after onset of fast, and upon sacrifice ( $12 \mathrm{hr}$ after test injection). At sacrifice, liver, spleen and brain specimens were fixed for fat staining, routine histology, and electron microscopy (EM). Plasma chemistry values were unchanged by fasting.

\begin{tabular}{|c|c|c|c|c|c|c|}
\hline RESULTS: & \multicolumn{3}{|c|}{ Baseline } & \multicolumn{3}{|c|}{12 Hrs After Test Injection } \\
\hline Group & C & E & FE & C & E & FE \\
\hline $\mathrm{NH}_{3} \mathrm{mM} / \mathrm{L}$ & $\overline{62.0}$ & $\overline{64 .}$ & $\overline{65.5}$ & $\overline{84.1}$ & $\overline{124.5}$ & $207.8 *$ \\
\hline $\mathrm{FFA} \mathrm{mM} / \mathrm{L}$ & 0.9 & 0.8 & 1.1 & 1.2 & $1.7 *$ & 1.6 \\
\hline Lactate $\mathrm{mM} / \mathrm{L}$ & $1.8:$ & 2.0 & 1.9 & 2.0 & 3.5 & 3.8 \\
\hline
\end{tabular}

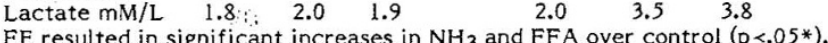
$\mathrm{FE}$ and $\mathrm{E}$ revealed increased microvesicular hepatic fat (without necrosis) $\mathrm{FE}$ and $\mathrm{E}$ revealed increased microvesicular hepatic fat (without necrosis) disruption in hepatic and splenic but not brain mitochrondria. SGOT, SGPT, and serum glucose were unchanged from baseline levels in all groups. Thus, FN depletion and EN administration produces metabolic, histologic, and ultrastructural changes similar to Reye's Syndrome.
1161

ZOONOSES IN EARLY INFANCY. Mary M. Zabala, Ranjendra Singh, Tahira Bokhari, Roger W. Cooper, Anthony Behrle). University of Medicine and Dentistry of New Jersey. Department of Pediatrics. Newark, New Jersey.

Zoonoses during early infancy have been infrequently reported in the pediatric literature. The spectrum of the disease in such affected infants ranges from mild disease such as gastroenteritis to the unusual forms involving the CNS. During a 16 month period, 3 infants less than 3 months of age were sean; 2 month period, 3 infants less than 3 months of age were sean; 2
patients ages 4 and 8 weeks respectively, developed septicemia and meningitis with blood and CSF cultures growing Pasturella multocida. Their hospital courses were complicated by seizures and delay in the identification of the organism. They were both treated with 2 weeks of IV antibiotics. Both infants had an unremarkable recovery with no neurological sequelae. A 3 week old infant was diagnosed to have Yersinia enterocolitica sepsis and was treated with appropriate IV antibodies. ATT 3 patients had close direct contact with pet dogs and one infant had a household adult contact whose nasopharynx grew Pasturella multocida. Epidemiological, clinical and serologic data obtained emphasized the high degree of association with household pets, especially dogs. The 3 cases reported have provided documentation of the occurrence of zoonoses in normal, non-immuno compromised infants and stresses the need to develop preventive measures in protecting the infant from exposure to such infectious agents.

AUGMENTED ANTIBODY (Ab) RESPONSES IN INFANTS ADMIN1162 ISTERED A NEW HAEMOPHILUS INFLUENZAE TYPE B CAPSULAR 112 POLYSACCHARIDE (PRP) DIPHTHERIA TOXOID CONJUGATE VACCINE (PRP-D). John M. Zahradnik and Lance K. Gordon, Baylor College of Medicine, Dept. of Microbiology \& Pediatrícs, Houston, Connaught Labs., Inc. Swiftwater, PA (Spons. by W.P. Glezen)
PRP-D, a hapten-carrier conjugate containing $20 \mu \mathrm{g} P R P / 0.5 \mathrm{cc}$, has previously been shown to be highly immunogenic in adults and young children (<18 mo.) given 2 doses. Ab responses in sera taken 1 mo. post-vac were evaluated in 90 infants administered PRP-D, PRP, or placebo at ages $3,5 \& 7$ months. No significant adverse reactions occurred. Anti-PRP responses for the vaccinees shown (Farr assay with SK standard) developed in $14 \%, 53 \%, \& 100 \%$ of PRP-D vaccinees respectively, following the first three doses as compared to $0,7 \%$, and $60 \%$ in PRP vaccinees respectively. A sequential increase in the mean anti-PRP titer was seen in the PRP-D group and final mean titers were 5-fold greater than that following PRP:

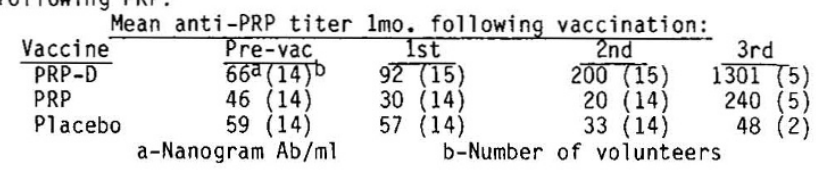

This new PRP-D conjugate vaccine appears to have resulted in an enhanced response since the seroconversion rate and $A b$ titers were higher than those seen following PRP.

\section{METABOLISM}

EFFECT OF 1, 25 DIHYDROXYCHOLECALCIFEROL $\left(1,25 \mathrm{D}_{3}\right)$

1163 ON LEUKocyte gama GLUTAMYL TRANSPEPTIDASE (GGTP). 1163 Carolyn Abitbol, Michael Freundlich, Gaston Zilleruelo, Kerst $i$ Thodenius and Jose Strauss. Department of Pediatrics, University of Miami, Miami, Florida.

GGTP is a membrane enzyme necessary in the transfer of some amino acids into the cytosol as a primary event in protein synthesis. Mechanisms of $1,25 \mathrm{D}_{3}$ in promoting protein synthesis in corporal cells need further elucidation. Circulating leukocytes offer a readily accessible modality for assay of cellular enzyme activity. We, therefore, studied the effects of $1,25 \mathrm{D}_{3}$ on growth and GGTP activity in young male wistar rats. The animals were allowed ad libitum feeding of standard Purina Lab Chow during a period of 21 days. Vitamin D supplemented animals received daily injections of $50 \mathrm{pMol} 1,25 \mathrm{D}_{3}$ in $0.2 \mathrm{ml}$ polyethylene glycol(PEG). Control animals were injected with $0.2 \mathrm{ml}$ PEG alone. At sacrifice, leukocyte GGTP was assayed. Growth parameters and enzyme activity are shown below: Growth parameters and enzyme activity are sh
(Mean+ S.D.; *Indicates Difference p $<0.05$ )

$$
\begin{gathered}
\text { Growth } \\
\text { Weight } \Delta \text { Body } \quad \Delta \text { Tail GCTP } \\
(G) \quad \text { Gength }(\mathrm{cm}) \mathrm{nM} / \mathrm{min} / \mathrm{mg}
\end{gathered}
$$$$
\text { (G) Length }(\mathrm{cm}) \text { Length }(\mathrm{cm}) \mathrm{nM} / \mathrm{min} / \mathrm{mg} \text { Protein }
$$

Control (10) $128 \pm 20 \quad 4.5 \pm .9 \quad 1.3 \pm .4 \quad 173+230$ Vit.D (10) $149+15 * 4.8+1.2 \quad 1.1+.5 \quad 116 \overline{0}+1721 *$ A tenfold increase in GGTP activity was noted in $1, \overline{2} 5 \mathrm{D}_{3}$ supplemented animals. Our study suggests an induction of GGTP activity in leukocytes by $1,25 \mathrm{D}_{3}$ which may, in turn, influence corporal protein synthesis. 